\title{
Toxic effects of hexaflumuron on the development of Coccinella septempunctata
}

\author{
Caihong Yu • Maoran Fu • Ronghua Lin • Yan Zhang • \\ Liu Yongquan • Hui Jiang • Theo C. M. Brock
}

Received: 2 May 2013 / Accepted: 22 July 2013 / Published online: 6 August 2013

(C) The Author(s) 2013. This article is published with open access at Springerlink.com

\begin{abstract}
Studying the toxic risk of pesticide exposure to ladybird beetles is important from an agronomical and ecological perspective since larval and adult ladybirds are dominant predators of herbivorous pest insects (e.g., aphids) in various crops in China. This article mainly deals with the long-term effects of a single application of the insect growth regulator hexaflumuron on Coccinella septempunctata. A 72$\mathrm{h}$ and a 33-day toxicity test with hexaflumuron (single application) were performed, starting with the second instar larvae of C. septempunctata. Exposure doses in the long-term experiment were based on the estimated 72-h acute $\mathrm{LR}_{50}$ (application rate causing $50 \%$ mortality) value of $304 \mathrm{~g}$ active ingredient (a.i.) ha $\mathrm{ha}^{-1}$ for second instar larvae of $C$. septempunctata. The long-term test used five hexaflumuron doses as treatment levels $(1 / 50,1 / 100,1 / 200,1 / 400$, and $1 / 800$ of the 72-h acute $\mathrm{LR}_{50}$ ), as well as a solvent control and blank control treatment. The measurement endpoints used to calculate no observed effect application rates (NOERs) included development time, hatching, pupation, adult emergence, survival, and number of eggs produced. Analyzing the experimental data with one-way analysis of variance showed that the single hexaflumuron application had significant effects on $C$. septempunctata endpoints in the 33-day test, including effects on development duration (NOER $1.52 \mathrm{~g}$ a.i. $\mathrm{ha}^{-1}$ ), hatching
\end{abstract}

\footnotetext{
Responsible editor: Laura McConnell

C. $\mathrm{Yu} \cdot \mathrm{M} . \mathrm{Fu}$

College of Chemistry and Environment Engineering, China

University of Mining and Technology (Beijing), 100083 Beijing, China

R. Lin $(\bowtie) \cdot$ Y. Zhang $\cdot$ L. Yongquan $\cdot$ H. Jiang Institute for the Control of Agrochemicals, Ministry of Agriculture, 100125 Beijing, China

e-mail: linronghua@agri.gov.cn

T. C. M. Brock

Alterra, Wageningen University and Research Centre, PO Box 47, 6700 Wageningen, The Netherlands
}

(NOER $3.04 \mathrm{~g}$ a.i. ha ${ }^{-1}$ ), pupation (NOER $3.04 \mathrm{~g}$ a.i. $\mathrm{ha}^{-1}$ ), and survival (NOER $1.52 \mathrm{~g}$ a.i. $\mathrm{ha}^{-1}$ ). These NOERs are lower than the reported maximum field application rate of hexaflumuron $\left(135 \mathrm{~g}\right.$ a.i. $\left.\mathrm{ha}^{-1}\right)$ in cotton cultivation, suggesting potential risks to beneficial arthropods.

Keywords Hexaflumuron · Coccinella septempunctata . Second instar · Acute toxicity · Long-term toxicity · Insect growth regulator $\cdot$ NOER

\section{Introduction}

Without effective crop protection, losses in agricultural production owing to pests, weeds, and diseases have been estimated to vary from 10 to $50 \%$ (Pimentel et al. 1992; Beddington 2010). Since chemical pesticides are intentionally released into the environment to protect crops from harmful insects, weeds, and pathogenic microorganisms, it is common practice to evaluate their side effects as part of the registration procedure when placing pesticides on the market (EU 1991). Ecological risk assessment is well advanced in developed regions of the world, which have adopted regulatory procedures to assess environmental risks of pesticides to nontarget terrestrial arthropods (e.g., Alix et al. 2012). The effects of pesticides on beneficial arthropods have been the subject of an increasing number of studies (Flexner et al. 1986; Sotherton et al. 1987; Yuxian et al. 2012). Among beneficial arthropods, natural enemies of pest organisms have received the greatest attention because of their value in integrated pest management (Haynes 1988; Dechaume-Moncharmont et al. 2003; Thompson 2003; Desneux et al. 2007). Integrated pest management in many agricultural ecosystems mainly depends on optimizing the control of pest organisms by predators and a prudent use of pesticides (Youn et al. 2003). As predators of aphids, ladybird beetles (and their larvae) have been reported to efficiently control aphids (Seo and Youn 2000; Seo and Youn 2002). 
However, the relationship between the survival of and ecosystem services provided by predators and their exposure to pesticides is not clear. To date, acute toxicity effects of some pesticides on ladybird beetles have been reported (Wu et al. 2007; Ji et al. 2011), but only a few studies have considered the long-term side-effects of pesticide application on ladybirds (Tongxian and Philip 2004; Yuxian et al. 2012).

The seven-spotted ladybird, Coccinella septempunctata L. (Coleoptera: Coccinellidae), is common in a wide range of natural and agricultural habitats, with worldwide distribution. Both the adult and larval stages are known to be highly polyphagous, feeding on Aphidoidea, Psylloidea, Coccoidea, and mites found on a variety of plants (Dolling 1991). It is a generalist, widespread and representative beneficial arthropod predator in China (Zhang et al. 2011). In addition, C. septempunctata is easy to be raised in the laboratory, making this species an ideal test organism to study the potential impacts of pesticides on beneficial arthropods as part of the registration procedure for pesticides.

New, more selective chemicals are being developed to reduce the environmental side-effects of pesticides. Insect growth regulators (IGRs) seem promising because of their more specific mode of action towards pest insects and their lower toxicity to nontarget organisms when compared with many conventional insecticides (Tongxian and Philip 2004; Nedjoua and Noureddine 2011). Hexaflumuron is a commonly used IGR in China with 120 products with hexaflumuron as the active ingredient having been registered and a usage of about $36 \mathrm{t}$ per year against insect pests in vegetables, fruit trees, forest trees, and other crops (till March 2013; http:// www.chinapesticide.gov.cn/service/aspx). In the USA, hexaflumuron is registered only as active ingredient in termite bait products because of its potential high risks to nontarget aquatic and terrestrial organisms (http:// msdssearch.dow.com/PublishedLiteratureDOWCOM/ dh_0886/0901b80380886a87.pdf?filepath=productsafety $/$ $\mathrm{pdfs} /$ noreg/233-00932.pdf\&fromPage $=$ GetDoc). Hexaflumuron is a benzoylphenylurea derivative (1-[3,5dichloro-4-(1,1,2,2 -tetrafluoroethoxy)phenyl]-3-(2,6difluorobenzoyl)urea), which interferes with chitin synthesis at the time of molting and is effective in controlling immature stages of insects. IGRs are generally considered compatible with natural enemy (beneficial arthropod) conservation (Desneux et al. 2007).

The present study aimed to investigate the sublethal, long-term effects of a single application of hexaflumuron on $C$. septempunctata, when applied to the second instar larvae. It also intends to help to promote the protection of ladybirds and to provide reference values for their possible use as a standard test species in prospective risk assessment for pesticides.

\section{Materials and methods}

\section{Pesticide}

The hexaflumuron content of the product used in the toxicity tests, which was obtained from our institute, is $95 \%$. As its water solubility is low, stock solutions were prepared by dissolving the substance using $0.1 \%$ Polysorbate 80 as a surfactant, prior to each experiment.

\section{Test species}

Second instar larvae of $C$. septempunctata were reared in the toxicity tests performed. The test organisms were obtained from a laboratory culture characterized by complete metamorphosis, consisting of the egg stage, four larval stages, pupa, and adult, mainly feeding on black bean aphid, Aphis craccivora Koch, which lived on Vicia faba L. C. septempunctata was reared in conditions of $20 \pm 1{ }^{\circ} \mathrm{C}, 50-70 \%$ relative humidity (RH) and 16:8 (light/dark (L/D)) photoperiod. The eggs hatched in 3 days at $25 \pm 1{ }^{\circ} \mathrm{C}, 70 \% \mathrm{RH}$ and $16: 8$ (L/D) photoperiod.

\section{Acute toxicity test method}

The test systems consisted of enclosures, each containing a pot filled with soil ( $11 \mathrm{~cm}$ in diameter) in which 10 broad bean plants (length $10 \mathrm{~cm}$ ) were planted. In each test system, 10 second instar ladybird larvae were introduced before insecticide spraying. The stock solution of hexaflumuron was prepared by dissolving the active ingredient with Polysorbate 80 . The hexaflumuron concentration measured in the stock solution approximated the intended concentration. Different test solutions were obtained by diluting the stock solution. The test solution was introduced to the test systems by spraying the plants, simulating the spray application on crops as closely as possible. An amount of $1.52 \mathrm{~mL}$ of test solution was sprayed toward the plants in each test system and the concentrations of active ingredient in the different test solutions used for the different treatments were $66,99,148,222,333$, and $500 \mathrm{mg} \mathrm{L}^{-1}$, respectively. The maximum field application rate normally used to control insect pests in cotton crops is $135 \mathrm{~g}$ active ingredient (a.i.) ha ${ }^{-1}$ (http://www.chinapesticide.gov.cn/ service/aspx/B3X.aspx?aiid=GRHEX). The application rates in the acute toxicity test were equivalent to $106,158,237,355$, 533, and $800 \mathrm{~g}$ a.i. ha ${ }^{-1}$. In addition, the experimental design included a blank control treatment, sprayed with distilled water, and a solvent control treatment, sprayed with a $0.1 \%$ Polysorbate 80 solution. Three replicates were used for each treatment. Mortality of ladybird larvae was recorded $72 \mathrm{~h}$ after treatment and the $\mathrm{LR}_{50}$ (the application rate causing $50 \%$ mortality among the test individuals) was calculated. The 
toxicity experiment was conducted in the laboratory at 20 $25^{\circ} \mathrm{C}, 50-70 \% \mathrm{RH}$, and 16:8 (L/D) photoperiod.

\section{Long-term toxicity test}

The test system of the long-term test was similar to that of the acute test, but the experimental design differed in that lower application rates (single application) were used, the observation period was extended to at least 33 days, several sublethal endpoints were monitored, and aphids (A. craccivora) were added to the test systems as food for the test animals every 2 days (until the prepupal stage of $C$. septempunctata). The hexaflumuron application rates were 1/50, 1/100, 1/200, 1/ 400 , and $1 / 800$ of the acute $\mathrm{LR}_{50}$ (derived from the acute toxicity test described above), and blank controls and solvent controls were again employed. Three replicates were used for each treatment, and 10 second instar larvae with the same size and morphological characteristics as those used in the acute test were introduced to each replicate test system. In each test system, an average of $1.52 \mathrm{~mL}$ of a solution containing different concentrations of hexaflumuron was sprayed onto the leaves of the broad bean plants. During spraying, the spraying device was located approximately $40 \mathrm{~cm}$ above the plants and care was taken that the solution of hexaflumuron was uniformly distributed over the leaves of the plants. After spraying, all the test systems were stored on the shelves in the climatized room at $20-25^{\circ} \mathrm{C}, 50-70 \% \mathrm{RH}$, and $16: 8$ (L/D) photoperiod. Measurement endpoints (development period, pupation percentage, hatching percentage, adult emergence, mortality, and egg production) were assessed and recorded at daily intervals until the second instar larvae of the next generation of C. septempunctata appeared. The total test duration was at least 33 days and covered the complete life cycle of $C$. septempunctata, from the second instar stage of the first generation (which was sprayed) to the second instar stage of the next generation. In the course of the experiment, the dates when the larvae became third instar, fourth instar, pupae, and adults were recorded as well as their numbers. At the end of the experiment, when surviving pupae had emerged, one male and one female adult ladybird were collected from each test system and placed in a plastic cage with a size of $20 \times 10 \times 7 \mathrm{~cm}$, together with sufficient $A$. craccivora (aphids) as food, and the number of eggs produced was recorded daily. A number of eggs were then collected from each cage (representing a specific test system) and placed in another climatized room at the same condition. The percentage of egg hatching was calculated by observing the number of larvae in each replicate.

Data analysis

The results obtained from the acute toxicity test allowed us to calculate the application rate that was lethal to $50 \%$ of the test animals, using prohibit analysis with SPSS software. The results of the long-term toxicity test did not allow an appropriate calculation of the $\mathrm{LR}_{50}$ (application rate leading to $50 \%$ mortality among the test individuals), since only partial effects (usually less than $50 \%$ ) were observed at the highest treatment levels. The results did, however, allow for the calculation of the no observed effect rate of application (NOER) by means of one-way analysis of variance (ANOVA). Fisher's least significant difference (LSD) tests were used to separate the differing means (Zar 1996).

\section{Results}

Acute toxicity

The $72 \mathrm{~h}$ acute $\mathrm{LR}_{50}$ values for hexaflumuron and $C$. septempunctata are shown in Table 1 . The regression equation was $y=-7.147+3.135 x, r^{2}=0.987$. The $\mathrm{LR}_{50}$ was $304 \mathrm{~g}$ a.i. $\mathrm{ha}^{-1}$, with a $95 \%$ confidence interval of $280-333 \mathrm{~g}$ a.i. $\mathrm{ha}^{-1}$.

\section{Long-term toxicity}

\section{Effect of hexaflumuron on survival rate of C. septempunctata}

Effects of a single application of hexaflumuron on the survival rate of larvae of $C$. septempunctata in the long-term toxicity test (test period 0-21 days) are reported in Fig. 1. There was no significant difference between the blank control and the solvent control. The survival started to decrease from the second day after treatment onwards at the two highest treatment levels. Compared with the blank control, the survival in test systems that had received 3.04 and $6.08 \mathrm{~g}$ a.i. $\mathrm{ha}^{-1}$ had decreased to 83.3 and $76.7 \%$, respectively, on day 6 after the insecticide application. At the end of the observation period for the larval stages (21 day), the survival in blank controls was $96.7 \%$ while that in the $6.08 \mathrm{~g}$ a.i. $\mathrm{ha}^{-1}$ treatment was $53.3 \%$. The 21 -day $\mathrm{LR}_{50}$ was calculated to be $6.08 \mathrm{~g}$ a.i. $\mathrm{ha}^{-1}$.

Table 1 Total initial number of second instar larvae of $C$. septempunctata in the acute toxicity test, and number and percentage of dead larvae $72 \mathrm{~h}$ after application of hexaflumuron in test systems that received different application rates $(n=3)$

\begin{tabular}{llll}
\hline Application rate $\left(\mathrm{g} \mathrm{a.i.} \mathrm{ha}^{-1}\right)$ & Total & $72 \mathrm{~h}$ dead & Mortality (\%) \\
\hline 0 & 30 & 0 & 0 \\
106 & 30 & 2 & 7 \\
158 & 30 & 5 & 17 \\
237 & 30 & 11 & 37 \\
355 & 30 & 19 & 63 \\
533 & 30 & 24 & 80 \\
800 & 30 & 26 & 87 \\
\hline
\end{tabular}


Fig. 1 Effects of a single application of hexaflumuron (gram per active ingredient per hectare) on the survival rate of $C$. septempunctata during a 21-day observation period in a laboratory toxicity test

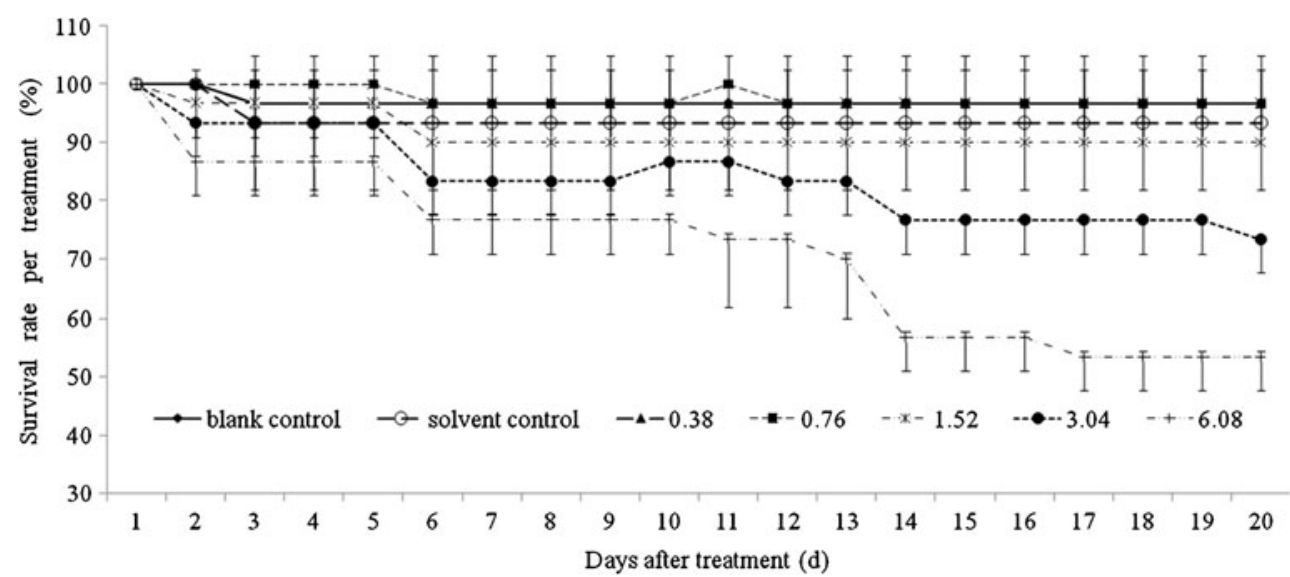

Differences between blank controls and the two highest treatment levels were significant (ANOVA, $p<0.05$; 21-day $\mathrm{NOER}=1.52 \mathrm{~g}$ a.i. $\mathrm{ha}^{-1}$ ).

\section{Effect of hexaflumuron on the development time of $C$. septempunctata}

The treatment-related effect of hexaflumuron on the development time of $C$. septempunctata (from second instar to second instar of the next generation) is presented in Table 2. The total developmental time in the controls was 28.43 days. Increasing hexaflumuron application rates were associated with larger delays in development. An NOER of $1.52 \mathrm{~g}$ a.i. ha ${ }^{-1}$ was calculated for the development time of the second instar. Treatment-related effects on development time were, however, relatively small, since the time at the highest treatment level (6.08 $\mathrm{g}$ a.i. $\mathrm{ha}^{-1}$ ) was only approximately a factor of 1.15 longer than that in the controls. At the highest treatment level, the development times of the second, third, fourth instar larvae, the pupae and the total generation were 2.60, 2.92, $5.77,6.80$, and 32.75 days, respectively, all significantly longer than in the controls. A NOER of $1.52 \mathrm{~g}^{\mathrm{a} . \mathrm{i}}$. ha ${ }^{-1}$ was calculated for the development time of the second instar larvae, while that for the other instar larvae was $3.04 \mathrm{~g}$ a.i. $\mathrm{ha}^{-1}$.

Effect of hexaflumuron on egg hatching of C. septempunctata

Observed treatment-related effects of hexaflumuron on the egg hatching percentage of $C$. septempunctata are presented in Fig. 2. The hatching percentage in the control test systems was $88.3 \%$. The lowest hatching percentage, $76.9 \%$, was observed in the test systems that received the highest dose, and was significantly different from that in controls $(\mathrm{NOER}=3.04-$ $\mathrm{g}$ a.i. ha ${ }^{-1}$ ). The mean hatching percentages in the other treatments were, in order of increasing dosage, 88.0, 88.7, 86.1 , and $83.57 \%$, but there was no significant difference compared to the controls.

\section{Effect of hexaflumuron on pupation of C. septempunctata}

Treatment-related effects of hexaflumuron on the pupation percentage of $C$. septempunctata are shown in Fig. 2. The pupation percentages in the control and hexaflumuron treatments up to $1.52 \mathrm{~g}$ a.i. ha ${ }^{-1}$ were $100 \%$. In the test systems that received $3.04 \mathrm{~g}$ a.i. $\mathrm{ha}^{-1}$, the mean pupation percentage

Table 2 Effect of hexaflumuron on the time of development (in days) of C. septempunctata in a long term toxicity test

\begin{tabular}{llllllllll} 
Treatment $\left(\mathrm{g}\right.$ a.i. $\left.\mathrm{ha}^{-1}\right)$ & \multicolumn{2}{l}{ Time of development (mean $\pm \mathrm{SD}$, days) } \\
\cline { 2 - 9 } & Second instar & Third instar & Fourth instar & Pupae & Pre-oviposition & Egg & First instar & Entire generation \\
\hline Blank control & $2.03 \pm 0.06$ & $2.33 \pm 0.12$ & $4.7 \pm 0.53$ & $6.03 \pm 0.12$ & $8.33 \pm 0.58$ & $3.00 \pm 0.00$ & $2.00 \pm 0.00$ & $28.43 \pm 0.21$ \\
Solvent control & $2.08 \pm 0.14$ & $2.325 \pm 0.04$ & $4.6 \pm 0.50$ & $6.23 \pm 0.31$ & $9.33 \pm 1.15$ & $3.00 \pm 0.00$ & $2.00 \pm 0.00$ & $29.61 \pm 1.63$ \\
0.38 & $2.07 \pm 0.06$ & $2.43 \pm 0.06$ & $4.83 \pm 0.21$ & $6.37 \pm 0.32$ & $9.00 \pm 1.00$ & $3.00 \pm 0.00$ & $2.00 \pm 0.00$ & $29.70 \pm 1.01$ \\
0.76 & $2.20 \pm 0.10$ & $2.50 \pm 0.10$ & $4.37 \pm 0.06$ & $6.40 \pm 0.20$ & $9.00 \pm 1.73$ & $3.00 \pm 0.00$ & $2.00 \pm 0.00$ & $29.47 \pm 1.60$ \\
1.52 & $2.12 \pm 0.06$ & $2.50 \pm 0.00$ & $4.83 \pm 0.67$ & $6.37 \pm 0.55$ & $9.33 \pm 0.58$ & $3.00 \pm 0.00$ & $2.00 \pm 0.00$ & $30.17 \pm 1.63$ \\
3.04 & $2.30 \pm 0.10^{*}$ & $2.53 \pm 0.16$ & $5.29 \pm 0.26$ & $6.45 \pm 0.40$ & $9.67 \pm 0.58$ & $3.00 \pm 0.00$ & $2.00 \pm 0.00$ & $31.23 \pm 0.18^{*}$ \\
6.08 & $2.60 \pm 0.10^{*}$ & $2.92 \pm 0.07^{*}$ & $5.77 \pm 0.31^{*}$ & $6.80 \pm 0.36^{*}$ & $9.67 \pm 1.53$ & $3.00 \pm 0.00$ & $2.00 \pm 0.00$ & $32.75 \pm 1.43^{*}$ \\
\hline
\end{tabular}

$p<0.05$, significant difference between treatment and control (ANOVA, LSD test) 
Fig. 2 Effect of different hexaflumuron doses on egg hatching rate, pupation rate and adult emergence rate of $C$. septempunctata. ${ }^{*} p<0.05$, significant difference between treatment and control (ANOVA, LSD test)

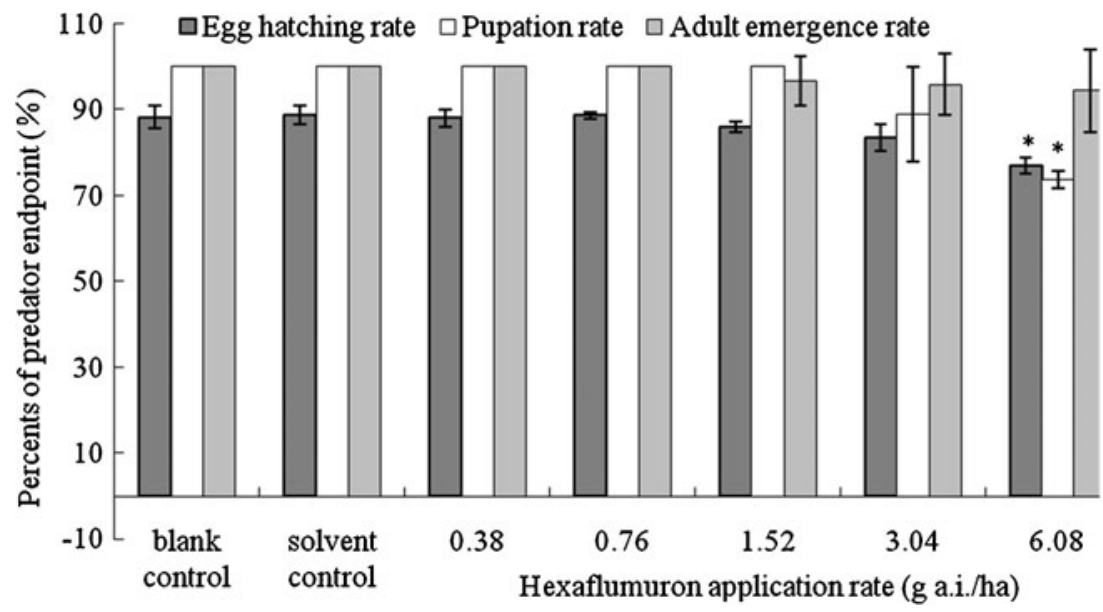

decreased to $88.9 \%$ (although not significantly different from controls). At the highest treatment level, the mean pupation percentage was $73.80 \%$, which was significantly different from that in the controls (ANOVA, $p<0.05$; NOER $=3.04 \mathrm{~g}$ a.i. $\left.\mathrm{ha}^{-1}\right)$.

\section{Effect of hexaflumuron on adult emergence of $C$.} septempunctata

Treatment-related effects of hexaflumuron on adult emergence of $C$. septempunctata are shown in Fig. 2. The emergence of $C$. septempunctata in the controls and at the two lowest treatment levels was $100 \%$. Mean emergence percentages in the test systems at the three highest treatment levels were $96.7,95.8$, and $94.4 \%$, respectively, relative to controls, although the difference was not statistically significant (ANOVA, $p>0.05$ ).

\section{Effect of hexaflumuron on egg production of $C$. septempunctata}

Figure 3 shows the mean number of eggs produced per female of $C$. septempunctata after hexaflumuron treatment. Each female produced a mean of 1,042 eggs in the controls, and numbers decreased with increasing dosages of the active ingredient applied, particularly at the two highest treatment

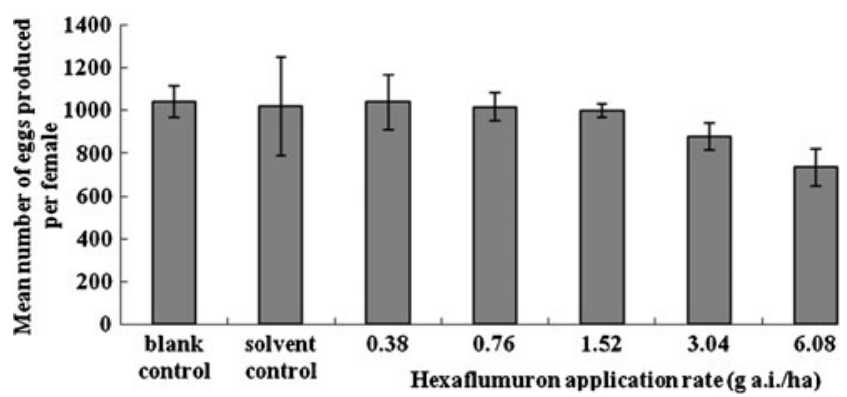

Fig. 3 Effect of different hexaflumuron doses on egg production per adult female of $C$. septempunctata levels. The lowest mean number of eggs per female was recorded at the highest treatment level (736 \pm 86 eggs), although this number was not significantly different from control values.

\section{Discussion}

Our 72-h acute toxicity test yielded an $\mathrm{LR}_{50}$ of $304 \mathrm{~g}$ a.i. ha ${ }^{-1}$ for second instar larvae of $C$. septempunctata exposed to the IGR hexaflumuron (single application). In the long-term toxicity test, the application rate causing approximately $50 \%$ mortality among ladybird larvae 21 days after a single application of hexaflumuron was a factor of 50 lower $(6.08 \mathrm{~g}$ a.i. ha $^{-1}$; Fig. 1). The long-term test lasted over 33 days and the NOERs for the endpoints of larval survival, development time for second instar larvae, and development time for the whole generation was $1.52 \mathrm{~g}$ a.i. $\mathrm{ha}^{-1}$. These data not only illustrate a relatively high acute/chronic ratio for hexaflumuron and $C$. septempunctata, but also the occurrence of delayed effects after a single application of this IGR.

A limitation of our study is that we could only express exposure-response relationships of hexaflumuron on $C$. septempunctata in terms of application rates, since we did not measure the fraction of the sprayed active ingredient that actually reached the bean plants, nor the dynamics in actual concentrations of hexaflumuron on the leaf surfaces and in the food items (aphids). The scientific literature reports that pesticide residuals both on surfaces (Hassan 1985) and in food (Angeli et al. 2000) may be important exposure routes for predatory insects. In our test systems, exposure of C. septempunctata probably occurred in the form of direct contact (spray droplets and residual contact activity on leaf surfaces) and ingestion of aphids (oral exposure). Although we did not investigate the different exposure routes in our test, our toxicity data clearly illustrate that potential effects of hexaflumuron on beneficial arthropods (including C. septempunctata) cannot be excluded 
at field application rates higher than $1.52 \mathrm{~g}$ a.i. $\mathrm{ha}^{-1}$. In China, the maximum field application rate of hexaflumuron to control pest insects on cotton was $135 \mathrm{~g}$ a.i. $\mathrm{ha}^{-1}$ in recent years (http:// www.chinapesticide.gov.cn/service/aspx/B3X.aspx?aiid= GRHEX). Our study does not allow a detailed evaluation of the long-term ecotoxicological consequences of this field application rate on $C$. septempunctata, since the highest application rate tested in our long-term toxicity test was $6.08 \mathrm{~g}$ a.i. ha ${ }^{-1}$.

Exposure to hexaflumuron is likely to perturb the development of the beneficial arthropod C. septempunctata, since it is an IGR that disrupts molting and cuticle formation and more generally acts on the insect's endocrine system (Dhadialla et al. 1998). In agreement with the results of our study, others have found adverse effects of hexaflumuron on the offspring of the beetle Callosobruchus maculatus, affecting its growth, development, and reproductive performance (Kellouche and Soltani 2006). Campiche et al. (2006) reported that hexaflumuron was highly toxic to a soil insect, Folsomia candida, with an $\mathrm{EC}_{50}$ of $0.6 \mathrm{mg} \mathrm{kg}{ }^{-1}$ (dry weight). Wang et al. (2008) showed that IGRs like hexaflumuron have chronic oral toxic effects on longevity, fecundity, and offspring emergence in the hymenopteran Anagrus nilaparvatae. Some studies reported that hexaflumuron causes higher toxicity in leaf miner insects than among predatory beneficial arthropods (Josep-Anton and Garcia-Marí 2001).

Our long-term toxicity test used five measurement endpoints to assess the effect of hexaflumuron on $C$. septempunctata, viz., survival rate, development time, pupation rate, adult emergence, number of eggs laid, and hatching rate. These measurement endpoints covered the whole life cycle as well as specific stages within the life cycle of $C$. septempunctata. In our study, the effect on the survival of $C$. septempunctata larvae (NOER of $1.52 \mathrm{~g}$ a.i. $\mathrm{ha}^{-1}$ ) was larger than the effects on pupation (NOER of $3.04 \mathrm{~g}$ a.i. $\mathrm{ha}^{-1}$ ), adult emergence (NOER $\geq 6.08 \mathrm{~g}$ a.i. $\mathrm{ha}^{-1}$ ) and hatching of eggs (NOER of $3.04 \mathrm{~g}$ a.i. $\mathrm{ha}^{-1}$ ). It has been reported that pesticide impacts on the development of predatory beneficial arthropods typically depend on the biology of the experimental species (i.e., predators versus parasitoids). Studies using parasitoids have often reported effects on adult emergence from the pupal stage (Krespi et al. 1991; Schneider et al. 2003; Saber et al. 2005). Cônsoli et al. (1998) reported that Trichogramma pretiosum pupae (Hymenoptera) displayed a higher sensitivity to pesticides in terms of development time than eggs, larvae, or prepupae.

The intensive use of conventional insecticides has caused undesirable side effects on the environment (Frank 2009). The more novel IGRs are reported to be more selective in their mode of action (Isshaya 1990; Dhadialla et al. 2005) and to be less harmful to most nontarget organisms, including arthropods (Mulla 1995). Although there has been considerable research to evaluate the efficacy of IGRs against target pest population, relatively little information is available concerning their toxicity to beneficial arthropods. Our study demonstrates that long-term effects of the IGR hexaflumuron on ladybird beetles cannot be excluded at field application rates higher than $1.52 \mathrm{~g}$ a.i. $\mathrm{ha}^{-1}$.

Acknowledgments This research was funded by financial assistance from the Special Fund for Agroscientific Research in the Public Interest (201203022), National Natural Science Foundation of China (no. 31171912), and the Chinese Ministry of Science and Technology (2011BAE06B09).

Open Access This article is distributed under the terms of the Creative Commons Attribution License which permits any use, distribution, and reproduction in any medium, provided the original author(s) and the source are credited.

\section{References}

Alix A, Bakker F, Barrett K, Brühl CA, Coulson M, Hoy S, Jansen J-P, Jepson P, Lewis G, Neumann P, Süssenbach D, Van Vliet P (2012) ESCORD 3. Linking Non-target arthropod testing and risk assessment with protection goals. SETAC Press, Society of Environmental Toxicology and Chemistry (SETAC), Pensacola, FL, p 136pp

Angeli G, Forti D, Maines R (2000) Side effects of eleven insect growth regulators on the predatory bug Orius laevigatus Fieber (Heteroptera: Anthocoridae). In: Vogt $\mathrm{H}$ and Heimbach U (ED), IOBC/WPRS Working Group Pesticides and Beneficial Organisms, Proceedings of the meeting at Versailles, France 27-29 October, 1999 IOBC/wprs Bulletin Vol. 22 (9): 85-92

Beddington J (2010) Food security: contributions from science to a new and greener revolution. Phil Trans R Soc B 365:61-71

Campiche S, Becker-van Slooten K, Ridreau C, Tarradellas J (2006) Effects of insect growth regulators on the nontarget soil arthropod Folsomia candida (Collembola). Ecotoxicol Environ Saf 63:216225

Cônsoli FL, Parra JRP, Hassan SA (1998) Side effects of insecticides used in tomato fields on the egg parasitoid Trichogramma pretiosum Riley (Hym., Trichogrammatidae), a natural enemy of Tuta absoluta (Meyrick) (Lep., Gelechiidae). J Appl Entomol 122:43-47

Dechaume-Moncharmont FX, Decourtye A, Hennequet-Hantier C, Pons O, Pham-Delègue MH (2003) Statistical analysis of honeybee survival after chronic exposure to insecticides. Environ Toxicol Chem 22:3088-3094

Desneux N, Decourtye A, Delpuech JM (2007) The sublethal effects of pesticides on beneficial arthropods. Annu Rev Entomol 52:81-106

Dhadialla TS, Carlson GR, Le DP (1998) New insecticides with ecdysteroidal and juvenile hormone activity. Annu Rev Entomol 43:545-569

Dhadialla TS, Retnakaran A, Smagghe G (2005) Insect growth and development disrupting insecticides. In: Gilbert LI, Gill S (eds) Comprehensive insect molecular science, vol 6. Pergamon, New York, pp 55-116

Dolling WR (1991) The Hemiptera. Oxford University Press, London, $p$ 274

EU (1991) Council Directive concerning the placing of plant protection products on the market. No. 91/414/EEC, Brussels, Belgium

Flexner JL, Lighthart B, Croft BA (1986) The effects of microbial pesticides on non-target, beneficial arthropods. Agric Ecosyst Environ 16:203-254

Frank SD (2009) Biological control of arthropod pests using banker plant systems: past progress and future directions. Biol Control 52:8-16 
Hassan SA (1985) Standard methods to test the side-effects of pesticides on natural enemies of insect and mites. OEPP/EPPO Bull 15:214 255

Haynes KF (1988) Sublethal effects of neurotoxic insecticides on insect behavior. Annu Rev Entomol 33:149-168

Isshaya I (1990) Benzoylphenyl ureas and other selective control agents: mechanism and application. In: Casida JE (ed) Pesticides and alternatives. Elsevier, Amsterdam, pp 365-376

Ji LL, Dong YK, Li ZH (2011) The indoor toxicity effect of four pesticides to the adult of Coccinella septempunctata. Shangdong Agric Sci 5:74-75 (in Chinese)

Josep-Anton J M, Garcia-Marí F (2001) Side-effects of pesticides on selected natural enemies occurring in citrus in Spain. In: Heidrun Vogt H, Viñuela E and Jacas J edited, IOBC/WPRS Working Group "Pesticides and Beneficial Organisms". IOBC/wprs Bulletin Vol. 24 (4): 103-112

Kellouche A, Soltani N (2006) Impact of hexaflumuron, a chitin synthesis inhibitor on growth, development and reproductive performance of the progeny in Callosobruchus maculatus after adult treatments. Afr J Agric Res 1(3):57-64

Krespi L, Rabasse JM, Dedryver CA, Nenon JP (1991) Effect of three insecticides on the life cycle of Aphidius uzbekistanicus Luz. (Hym., Aphidiidae). J Appl Entomol 111:113-119

Mulla MS (1995) The future of insect growth regulators in vector control. J Am Mosq Control Assoc 11(2):269-273

Nedjoua Z, Noureddine S (2011) Environmental risks of two chitin synthesis inhibitors on Gambsia affinis: chronic effects on growth and recovery of biological responses. Biol Control 59:106-113

Pimentel D, Acquay H, Biltonen M, Rice P, Silva M, Nelson J, Lipner V, Giordano S, Horowitz A, D'Amore M (1992) Environmental and economic costs of pesticide use. BioScience 42(10):750-760

Saber M, Hejazi MJ, Kamali K, Moharramipour S (2005) Lethal and sublethal effects of fenitrothion and deltamethrin residues on the egg parasitoid Trissolcus grandis (Hymenoptera: Scelionidae). J Econ Entomol 98:35-40

Schneider MI, Smagghe G, Gobbi A, Vinuela E (2003) Toxicity and pharmacokinetics of insect growth regulators and other novel insecticides on pupae of Hyposoter didymator (Hymenoptera:
Ichneumonidae), a parasitoid of early larval instars of lepidopteran pests. J Econ Entomol 96:1054-1065

Seo MJ, Youn YN (2000) The Asian ladybird, Harmonia axyridis, as biological control agents: I. Predacious behavior and feeding ability. Kor J Appl Entomol 39:59-71

Seo MJ, Youn YN (2002) Effective preservation methods of the Asian, Harmonia axyridis (Coleoptera: Coccinellidae), as an application strategy for the biological control of aphid. J Asia-Pacific Entomol 5:209-214

Sotherton NW, Moreby SJ, Langley MG (1987) The effects of the foliar fungicide pyrazophos on beneficial arthropods in barley fields. Annals Appl Bio 111:75-87. doi:10.1111/j.1744-7348.1987.tb01435.x

Thompson HM (2003) Behavioural effects of pesticides in bees: their potential for use in risk assessment. Ecotoxicology 12:317-330

Tongxian L, Philip AS (2004) Lethal and sublethal effects of two insect growth regulators on adult Delphastus catalinae (Coleoptera: Coccinellidae), a predator of whiteflies (Homoptera:Aleyrodidae). Biol Control 30:298-305

Wang HY, Yang Y, SU JY, Shen JL, Gao CF, Zhu YC (2008) Assessment of the impact of insecticides on Anagrus nilaparvatae (Pang et Wang) (Hymenoptera: Mymanidae) an egg parasitoid of the rice planthopper, Nilaparvata lugens (Hemiptera: Delphacidae). Crop Prot 27:514-522

Wu HB, Zhang F, Wang SQ, Zhang JM (2007) The sensitivity test of several insecticides to Harmonia axyridis. Chin J Biol Control 23(3):213-217 (in Chinese)

Youn YN, Seo MJ, Shin JG, Jang C, Yu YM (2003) Toxicity of greenhouse pesticides to multicolored Asian lady beetles, Harmonia axyridis (Coleoptera: Coccinellidae). Biol Control 28:164-170

Yuxian H, Jianwei Z, Yu Z, Nicolas D, Kongming W (2012) Lethal effect of imidacloprid on the coccinellid predator Serangium japonicum and sublethal effects on predator voracity and on functional response to the whitefly Bemisia tabaci. Ecotoxicology 21:1291-1300

Zar JH (1996) Biostatistical analysis, 3rd edn. Prentice, London, UK, p 662

Zhang DW, Dong M, Du XG (2011) Effects of organic management on predator densities of Myzus persicae (Sulzer) during transition to organic agriculture in peach fields in China. J Sustain Agricul 35(8):826-839 